\title{
Experimental and Numerical Study of Energy Losses in a Barbecue Oven in Burkina Faso
}

\author{
Gaël Lassina Sawadogo', Serge Wendsida Igo², Abdoulaye Compaore², \\ Drissa Ouedraogo ${ }^{1}$, Xavier Chesneau ${ }^{3}$, Belkacem Zeghmati ${ }^{3}$
}

\begin{abstract}
${ }^{1}$ Laboratoire d'Energies Thermiques Renouvelables (LETRE), Université Pr Joseph KI-ZERBO, Ouagadougou, Burkina Faso ${ }^{2}$ Département Energie, Institut de Recherche en Sciences Appliquées et Technologies (IRSAT), Ouagadougou, Burkina Faso ${ }^{3}$ Laboratoire de Mathématiques et Physique (LAMPS), Université de Perpignan Via Domitia (France), Perpignan, France Email: bemagael@gmail.com
\end{abstract}

How to cite this paper: Sawadogo, G.L., Igo, S.W., Compaore, A., Ouedraogo, D., Chesneau, X. and Zeghmati, B. (2020) Experimental and Numerical Study of Energy Losses in a Barbecue Oven in Burkina Faso. Open Journal of Energy Efficiency, 9, 31-52.

https://doi.org/10.4236/ojee.2020.91003

Received: January 1, 2020

Accepted: March 17, 2020

Published: March 20, 2020

Copyright $\odot 2020$ by author(s) and Scientific Research Publishing Inc. This work is licensed under the Creative Commons Attribution International License (CC BY 4.0).

http://creativecommons.org/licenses/by/4.0/

\begin{abstract}
This work concerns an experimental and numerical study of energy losses in a typical oven usually used in the agro-food craft sector in Burkina Faso. The experimental results were obtained by infrared thermography of the oven and by monitoring the evolution of the wall temperatures using thermocouples connected to a data acquisition system. These results indicate that the energy losses are mainly through the walls of the oven. The numerical study based on the energy balance and corroborated by the experimental study made it possible to quantify these losses of energy which represents almost half of the fuel used. These results will allow us to work on a new, more efficient oven model for the grilling sector in Burkina Faso.
\end{abstract}

\section{Keywords}

Grill, Oven, Optimization, Energy Losses, Nodal Method

\section{Introduction}

In developing countries, the common energy source consists of biomass, which is becoming increasingly rare [1]. Indeed, several studies in the energy and environment sector are sounding the alarm about the degraded state of forest resources and its consequences on climate change [2] [3] [4] [5] [6]. The World Food Program (WFP) has estimated at 105,000 ha the regression rate of forest formations in Burkina while the Ministry of Environment and Sustainable Development stands at 107,626 ha/year [7].

In order to reduce biomass consumption, several energy-saving technologies have been developed. Indeed, from three (03) stones fireplace up to its improved 
version, efforts have been made especially for domestic cooking [8]. At the national level, the catalog of innovations includes several types of improved fireplaces with wood, charcoal and butane gas [9] [10]. As energy wood is increasingly scarce, researchers have tested fuels such as animal excrement [11], ethanol [12], rice crosses [13], paraffin [14] and so on. In addition, researchers have long prioritized sheet metal because of their low thermal inertia and their ease of access [15] [16]. For domestic use, this is practical because they are shock-resistant and easily transportable, but the efficiency of households between $15 \%$ and $17 \%$ is low [17]. On the other hand, for grilling activities, it is very important to take into account energy losses as well as the service life of the oven. In fact, the use of iron sheet increases energy losses and exposes the users to very high temperatures. In addition, the ovens, subjected to high temperatures, degrade very quickly [18]. As a result, energy, sanitary and hygienic constraints have been identified on the different technologies [19] [20]. These ovens consume huge amounts of charcoal and operate for a long time. Unfortunately, the techniques of charcoal production at the national level have very low performance (around 20\%) [21].

In Burkina Faso, the low energy efficiency of the ovens has a negative impact on the grilling sector because the energy losses represent net losses of revenue for the actors.

Unfortunately, there are no scientific studies which highlight this problem.

Therefore, the main objective of this work is to quantify the energy losses generated by these equipments through an experimental and numerical study. The results obtained should later motivate work to improve the energy efficiency of grilling equipment in Burkina Faso.

\section{Experimental Study}

\subsection{Materials and Methods}

\subsubsection{Materials}

A set of experimental equipment was used to characterize the thermal behavior of the most used oven model. We have among others:

- An oven made of iron sheets identical to the most common model. The dimensioning is done according to the needs of the user. In these ovens the charcoal is directly in contact with all the walls which have a thickness of 2 $\mathrm{mm}$. The charcoal pan of our oven has the following dimensions: $1.2 \mathrm{~m} \times 0.5$ $\mathrm{m} \times 0.2 \mathrm{~m}$.

Figure 1 shows the oven and Figure 2 its diagram.

- Temperature recorders and thermocouples of type $\mathrm{K}$ (precision: $1.5^{\circ} \mathrm{C}$ ), a precision balance (precision: $1 \mathrm{~g}$ ), a RAYCAM thermal imaging camera with measurement uncertainty of $2^{\circ} \mathrm{C}$ and a combustion analyzer.

\subsubsection{Methods}

Four kilograms of charcoal were introduced into the oven corresponding for a grilling cycle. Before starting the charcoal burning, thermocouples were placed on the outer walls of the oven, on the grate and inside the combustion chamber. 


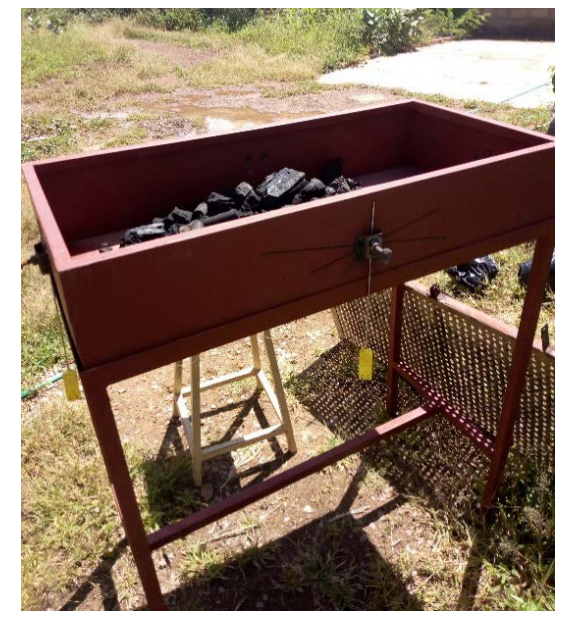

Figure 1. Metallic oven.

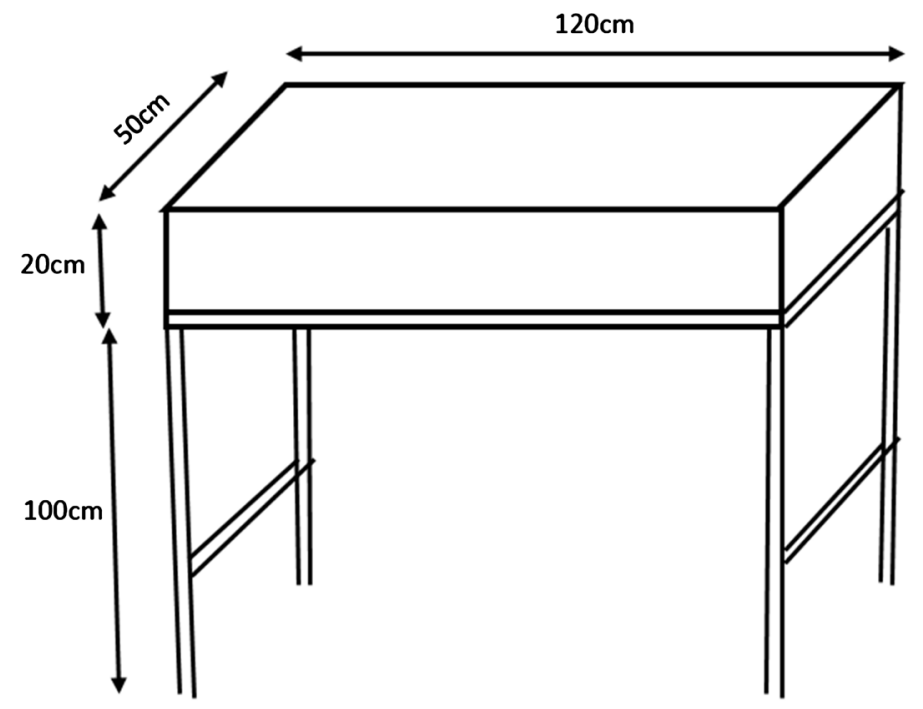

Figure 2. Diagram of the metal oven.

The infrared captures of the oven, made at intervals of five (05) minutes, allows to follow temperature distribution on the external walls of the oven. The measurements were repeated sufficiently under the same conditions in order to have average values. The experiment has a duration of two (02) hours and at the end of each experiment, the charcoal has been extinguished, dried and weighed to determine the mass of fuel burned. In addition, we also monitor the production of gases such as carbon monoxide $(\mathrm{CO})$, carbon dioxide $\left(\mathrm{CO}_{2}\right)$, methane $\left(\mathrm{CH}_{4}\right)$, dihydrogen ratio on the dinitrogen (H2:N2) to analyze the quality of the combustion. Figure 3 shows the experimental device and Figure 4 the diagram of the experimental device.

\subsection{Results and Discussion}

\subsubsection{Evolution of the Temperatures of the Different Parts of the Oven} The profiles represented are averages of the temporal evolutions of the temperatures of the various places of the oven. Standard deviations on measurements were also represented. 
Figures 5-8 show that the maximum standard deviations of the temperatures of the different places of the oven do not have the same values. Indeed, that of the combustion temperature is $34^{\circ} \mathrm{C}$ and a maximum relative uncertainty of $7.34 \%$.

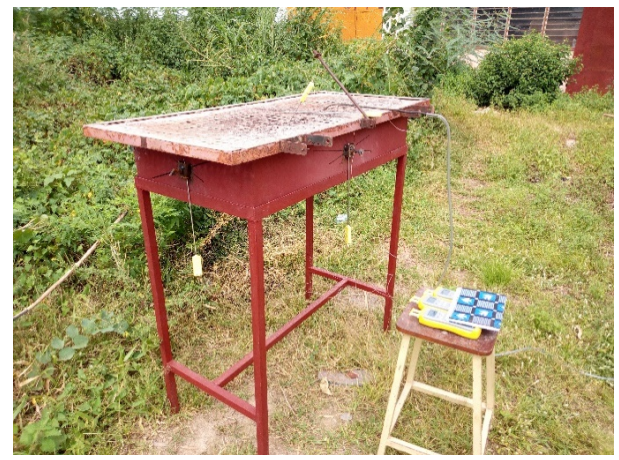

Figure 3. Experimental device.

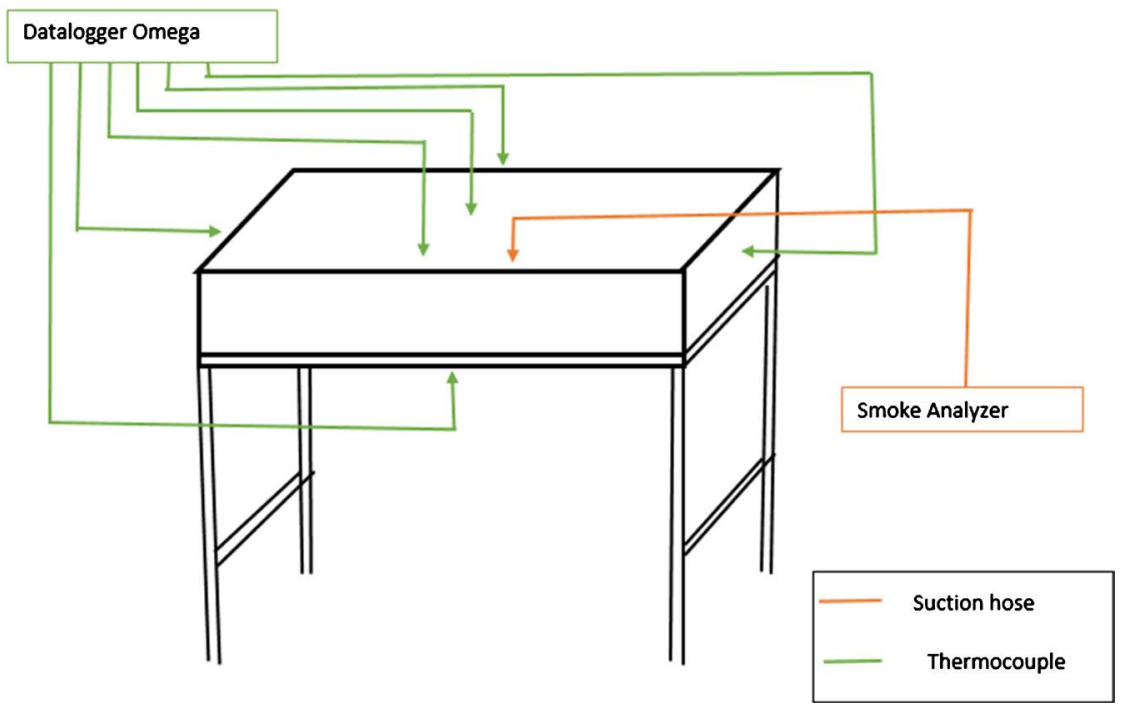

Figure 4. Experimental device.

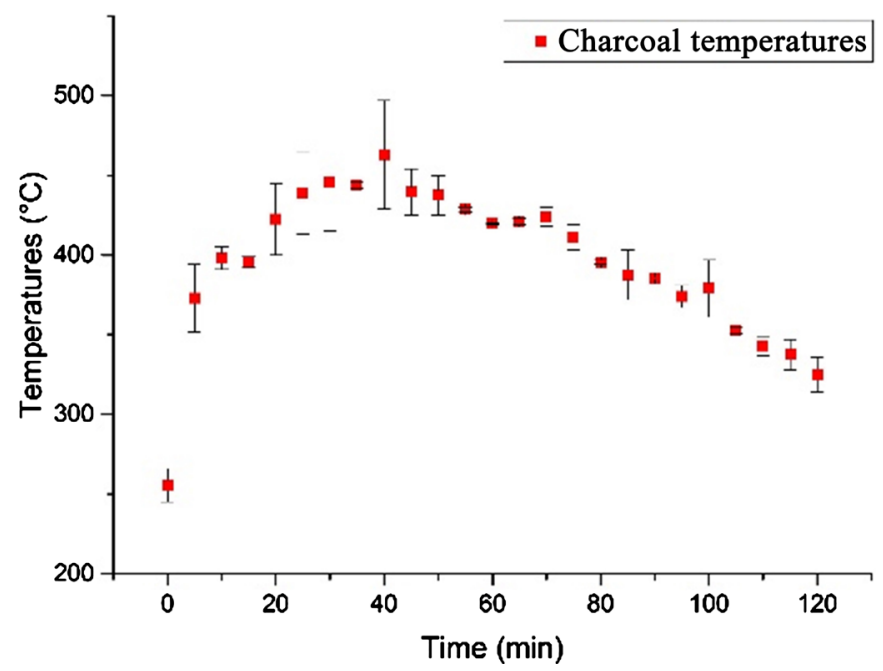

Figure 5. Temporal evolution of average combustion temperatures. 


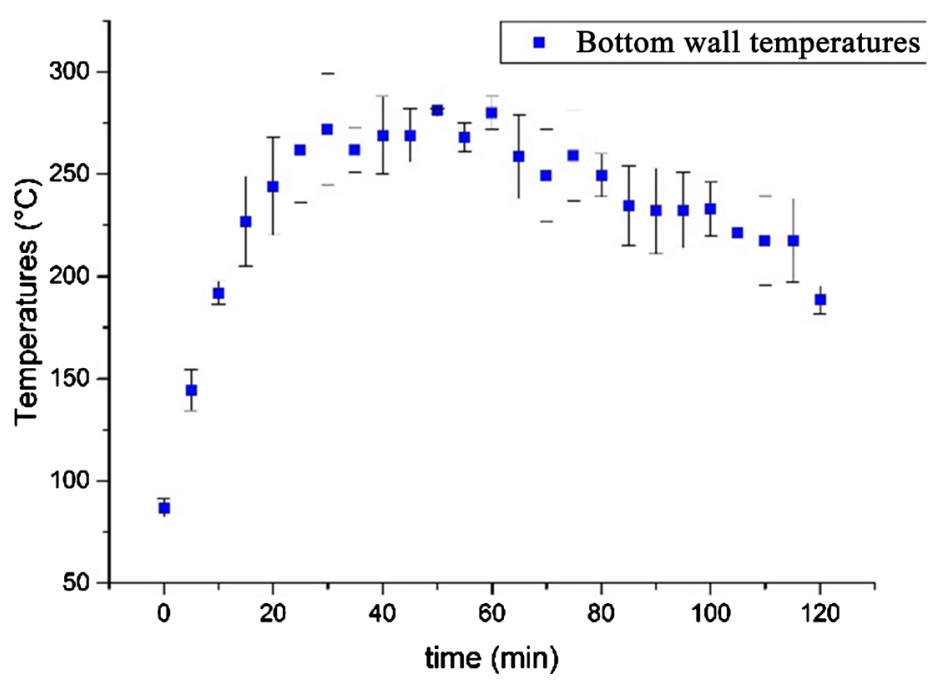

Figure 6. Temporal evolution of average temperatures of the bottom wall.

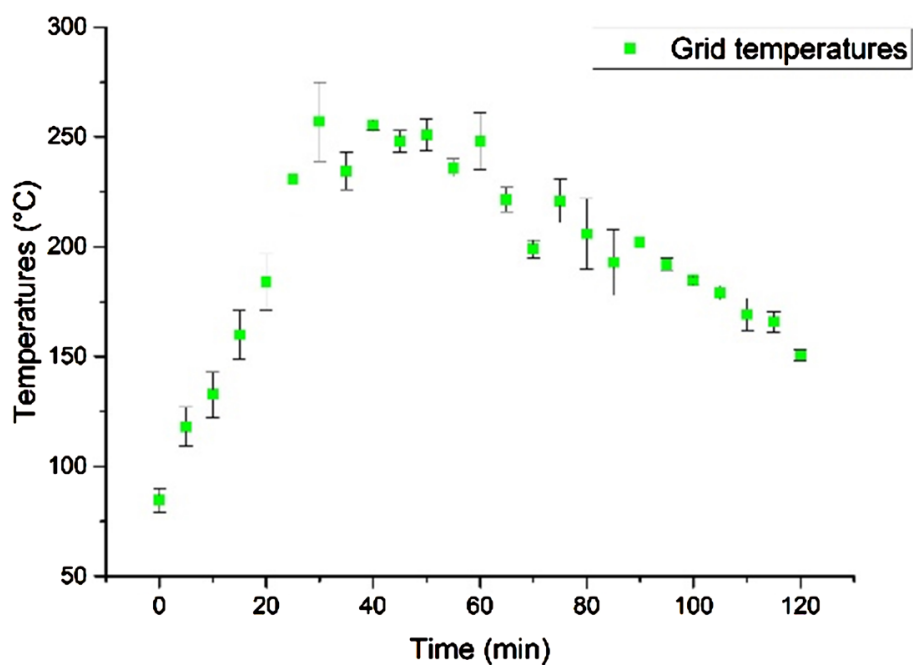

Figure 7. Temporal evolution of the average temperatures of the grid.

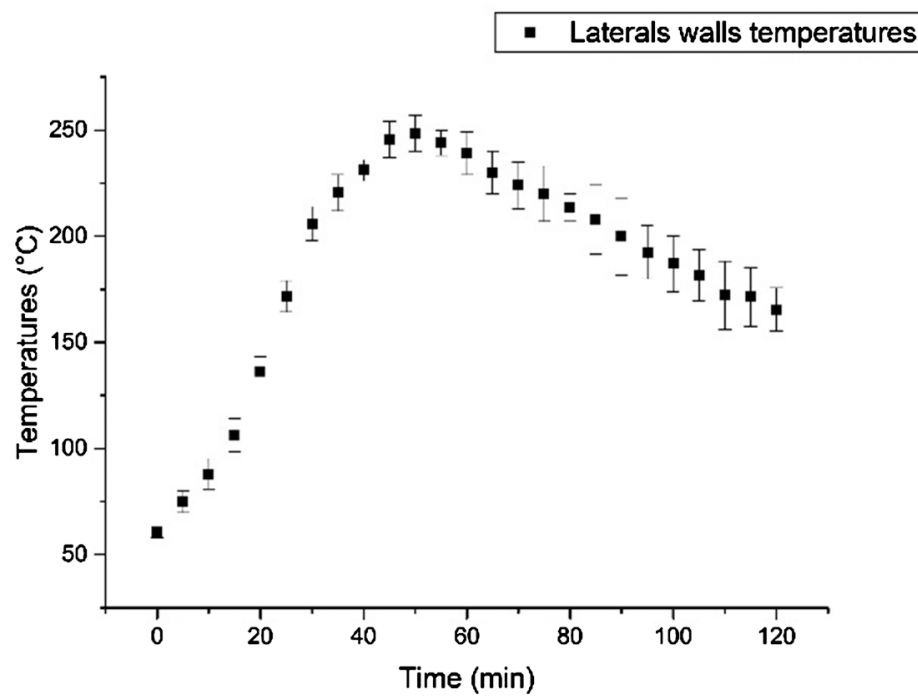

Figure 8. Temporal evolution of lateral mean parietal temperatures. 
For grid temperatures the maximum standard deviation is $16.5^{\circ} \mathrm{C}$ and a maximum relative uncertainty of $7.77 \%$. The temperatures below the oven have a maximum standard deviation of $25.5^{\circ} \mathrm{C}$ and a maximum relative uncertainty of 9.98\%. Sidewall temperatures have a standard deviation of $18.75^{\circ} \mathrm{C}$ and a maximum relative uncertainty of $9.08 \%$. These values of the errors were obtained at the beginning of the experiments, which is to say for the low values of the temperatures.

The standard deviations are a little big for the cave and grid temperatures because the experiments on the oven are very sensitive to external conditions. Indeed, the direction and the speed of the wind, its humidity are elements which influence not only on the combustion but also on the temperatures of the walls. These factors are very random depending on the seasons, days, hours and even minutes. A change of speed or wind direction can cause large temperature variations. In addition, these variations are also due to the heterogeneity of charcoal which comes from different woods in most cases. These variations show the difficulty that lies in the experiments using ovens in the conditions of the broiler. Indeed, several studies show that many factors can influence enormously on the stove experimental studies [22] [23] [24].

\subsubsection{Global Report}

To make an interpretation of the overall operation of the oven we have represented the evolution of the temperatures at different places of the oven.

From Figure 9, it can be seen that the temperatures of the different parts of the oven have the same behavior than that of the fuel. However, these temperatures are at about $200^{\circ} \mathrm{C}$ lower than that of the oven. The temperature under the oven remains greater than those of the side walls and those of the grid. The side

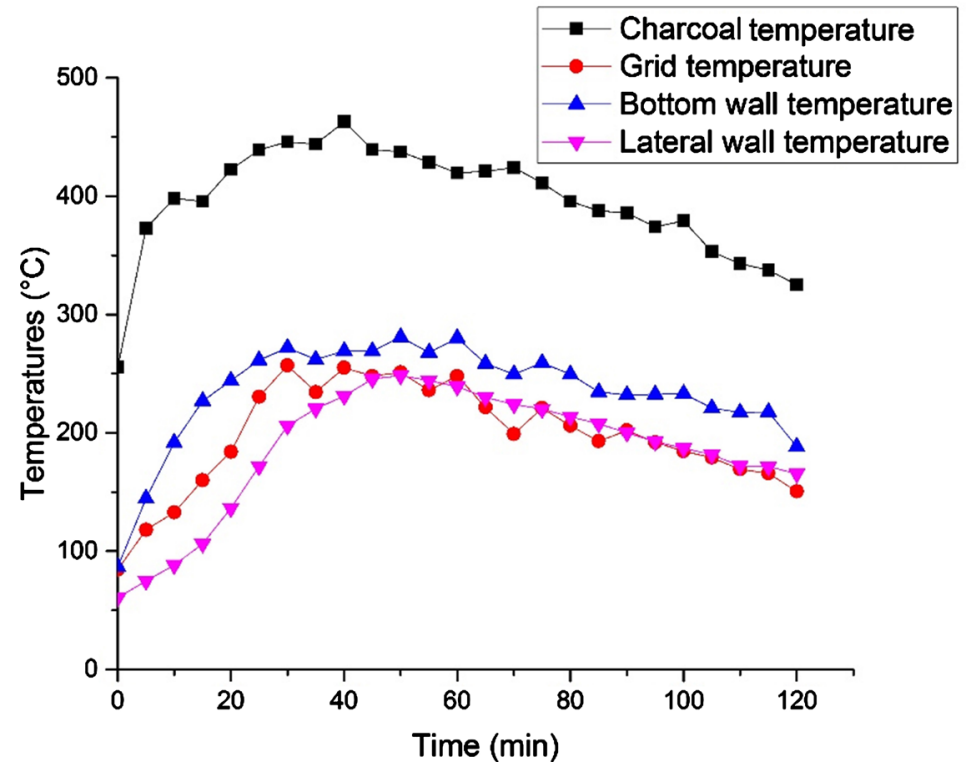

Figure 9. Temporal evolutions of the profiles of the average temperatures of the various places of the oven. 
wall temperatures increase from $60.7^{\circ} \mathrm{C}$ to $248.5^{\circ} \mathrm{C}$, and then decrease more slowly to $165.5^{\circ} \mathrm{C}$ after two hours of experiments. Temperatures under the charcoal tank increased from $86.8^{\circ} \mathrm{C}$ to $269^{\circ} \mathrm{C}$ during 45 minutes and decreased to $188.45^{\circ} \mathrm{C}$. Note that the temperatures of the side walls remain higher than those of the bottom wall during the experiments. This difference in temperature is explained by the fact that the fuel rests on the bottom wall during the whole experiment.

The temperature of the grate also increases with the heat generated by the charcoal and it decreases as the temperature of the fuel decreases. It increases from $84.5^{\circ} \mathrm{C}$ to $257^{\circ} \mathrm{C}$ during the first 45 minutes and then decreases to $150.6^{\circ} \mathrm{C}$. The temperature oscillations of the grid are due to the gusts of wind which arrive at random. It is on this grid that the products to be grilled must be placed. The temperatures of the different walls as well as that of the grid are close; therefore, indicating that the heat lost by the different walls is the same available at the grid. The high thermal conductivity of the iron sheet facilitates thermal losses, hence the low energy efficiency of the oven. The temperature of the gate is close to that of the side walls and remains even below that of the wall from below the oven while it should be the hottest part after the fuel temperature. This clearly shows that this type of oven, although it is more used, is not energy efficient and therefore contributes to the waste of the country's energy resources, which are becoming increasingly rare. The heat produced by the fuel must be confined and directed towards the grid but is lost through the walls of the oven.

\subsubsection{IFR Captures of the Oven}

In order to support our analysis in the first part, we will view a few shots of the thermal camera shown through Figures 10-15 and make brief interpretations.

It is noted that at the beginning of the combustion of the charcoal, the heat generated is distributed on the grid and on the outer wall of the oven. Obviously,
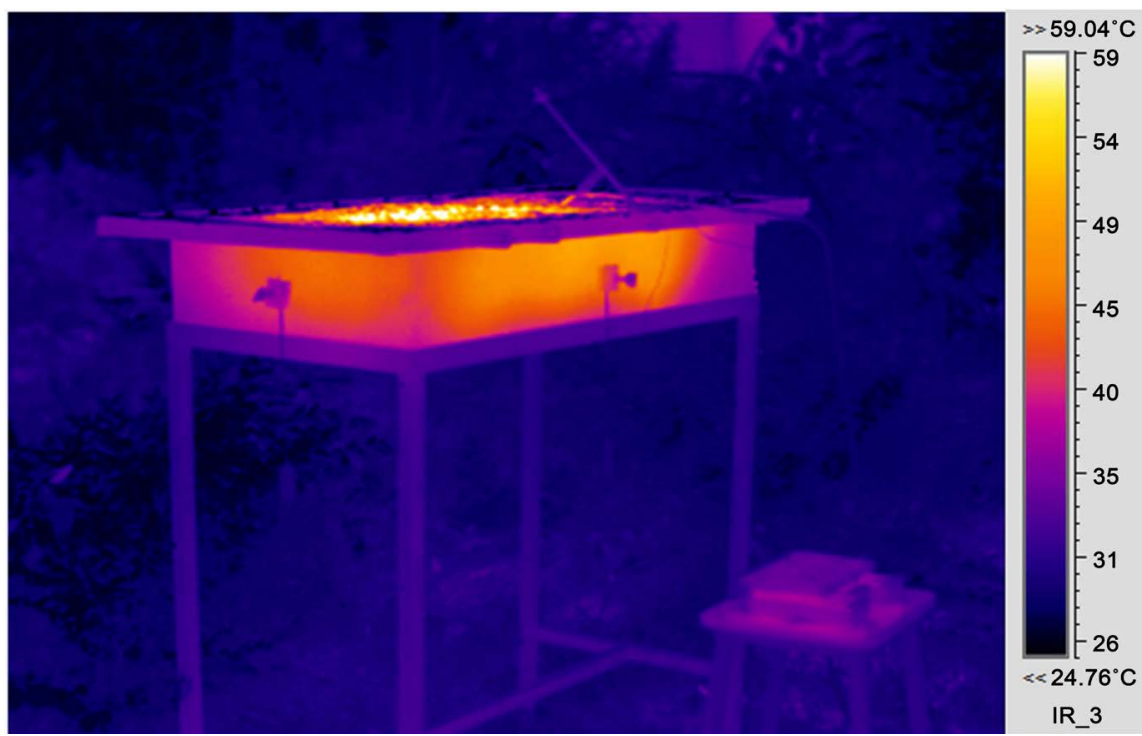

Figure 10. Beginning of the experiment. 


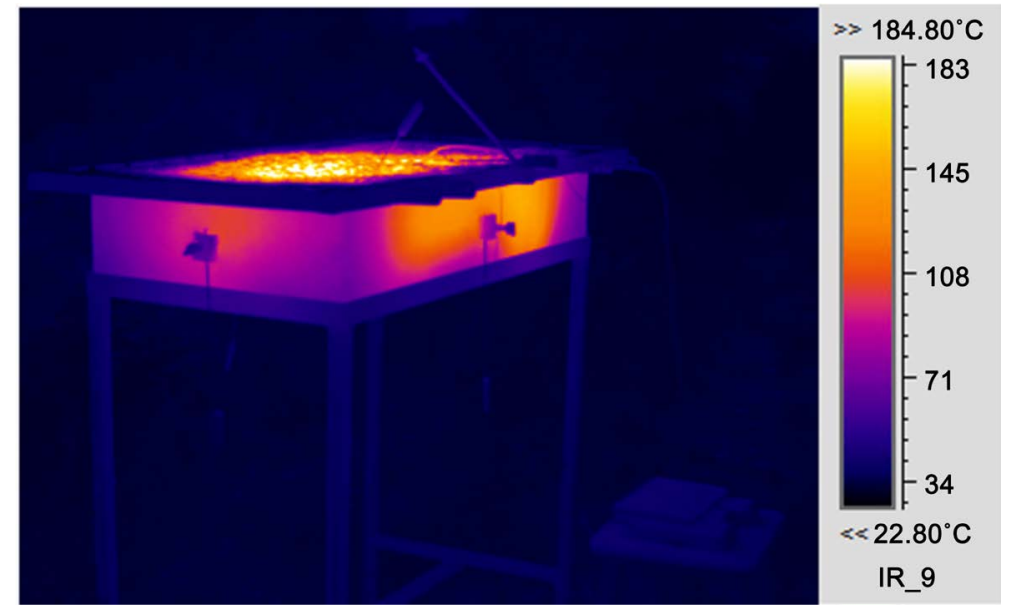

Figure 11. 20 minutes after the start of the experiment.
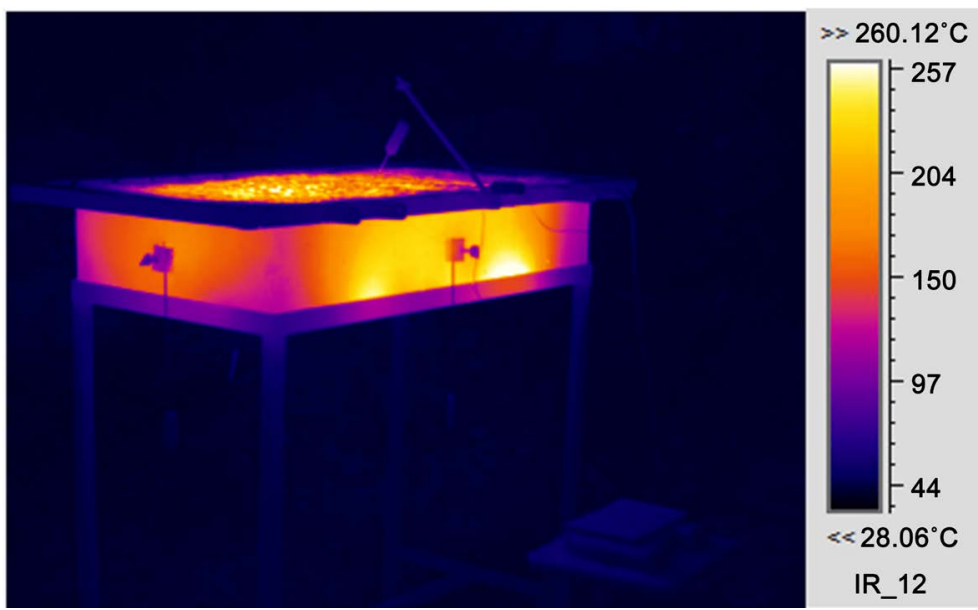

Figure 12. 40 minutes after the start of the experiment.
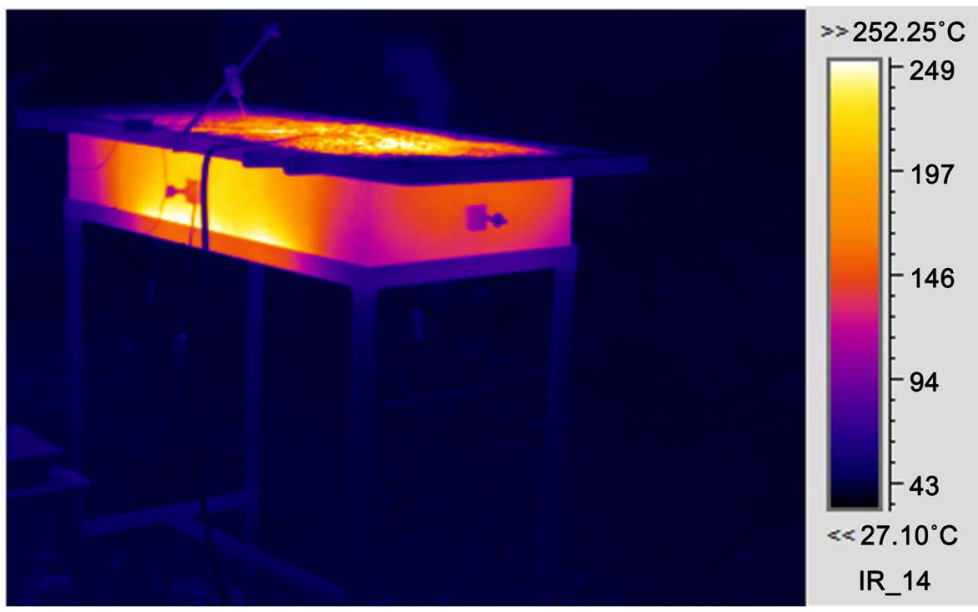

Figure 13. 60 minutes after the start of the experiment.

the thermal energy seen on the wall will be lost by convective and radiative exchanges. The other thermograms show that this very important flow increases with time until about 40 minutes and then decreases slightly until the end of the 


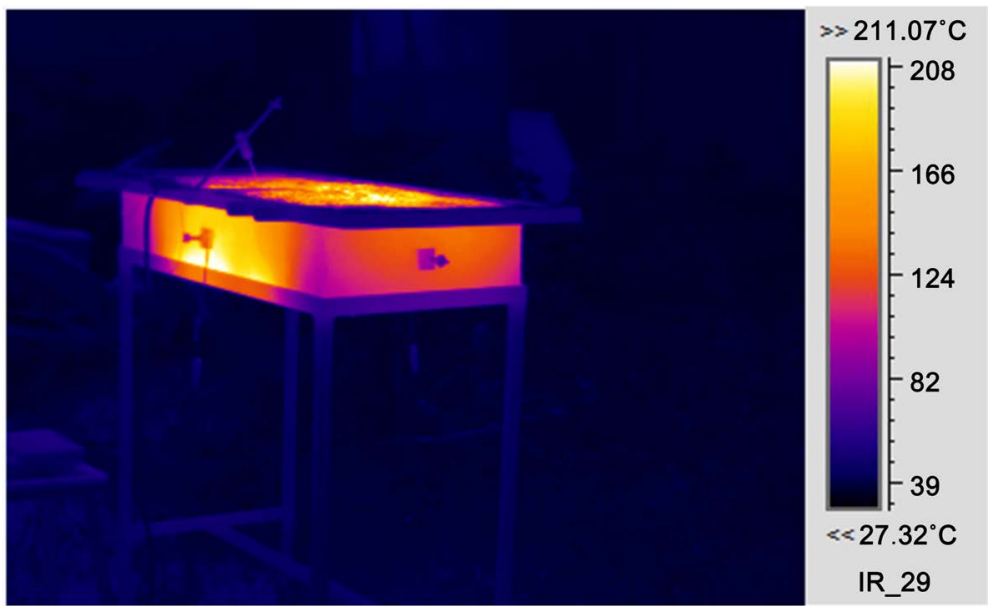

Figure 14. 90 min after the start of the experiment.
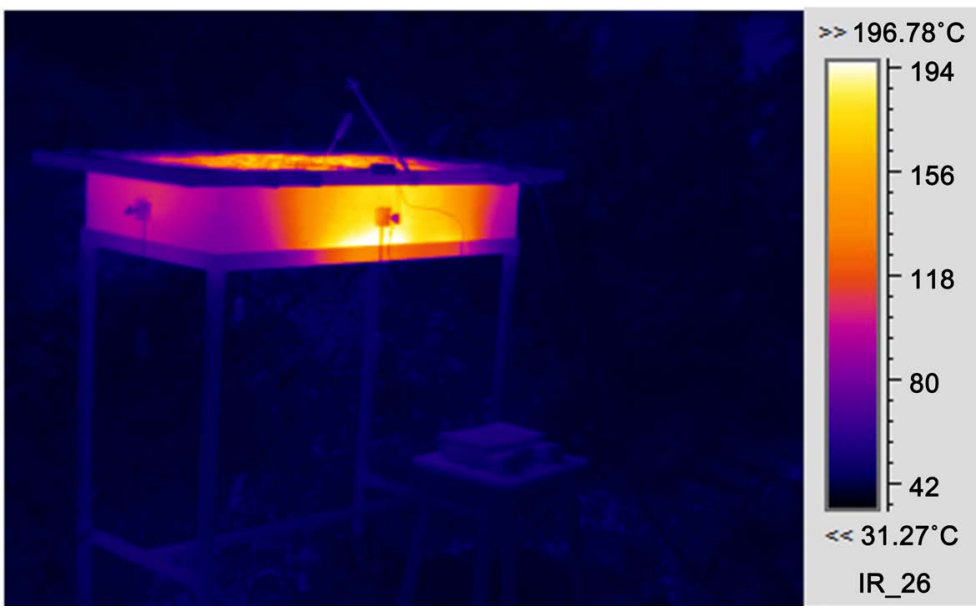

Figure 15. $120 \mathrm{~min}$ after the start of the experiment.

experiment. This heat is a loss of energy for grilling. Another consequence will be the thermal discomfort felt by the users. In fact, users exposed to high temperatures are subject to many diseases but to injuries due to contact with the walls of the oven which are very hot. These thermograms highlight the poor energy efficiency of this type of grill oven.

\subsubsection{Analysis of Combustion}

The quality of the combustion can be determined from the gases produced. Figure 16 shows the different proportions of the gases produced by combustion as a function of time.

The maximum standard deviations of the measurements are $0.2 \%$ for $\mathrm{CO}_{2}$, $0.1 \%$ for $\mathrm{CO}$ and $0.01 \%$ for $\mathrm{CH}_{4}$ and $\mathrm{H} 2: \mathrm{N} 2$. The presence of carbon monoxide indicates incomplete combustion although the grate is not loaded. This is due to insufficient air intake because for good combustion it takes an excess of air. In addition, the air entering from the top to the countercurrent with the burnt gas reduces its diffusion in the tray and causes incomplete combustion with a combustion bed essentially above. 


\section{Numerical Study}

\subsection{Physical Model}

The oven consists essentially of a casing sheet iron. We considered the same dimensions as those of the study of the experimental study. The combustion chamber shown in Figure 17 will be modeled by likening it to a semi-open enclosure on its upper wall. It has a parallelepiped shape and the six (06) faces have been noted from $A$ to $F$. the air inlets and the outputs of the burned gases are from the top.

\subsection{Mathematical Model}

\subsubsection{Numerical Method}

The use of this method requires the definition of a common parameter in solid and fluid regions: thermal conductance. The description of the main steps of the realization of this modelization is the following one [25]:

- Cutting the system into elementary blocks. Much of the value of the model is based on the quality of the block division.

- Determination of the different internal heat transfer modes associated with the blocks of the studied system. The blocks are defined by the nature of the materials or an equivalence and/or heat exchange modes. The analysis of these exchanges leads to installing between the nodes (centers of the blocks) connections called thermal conductors.

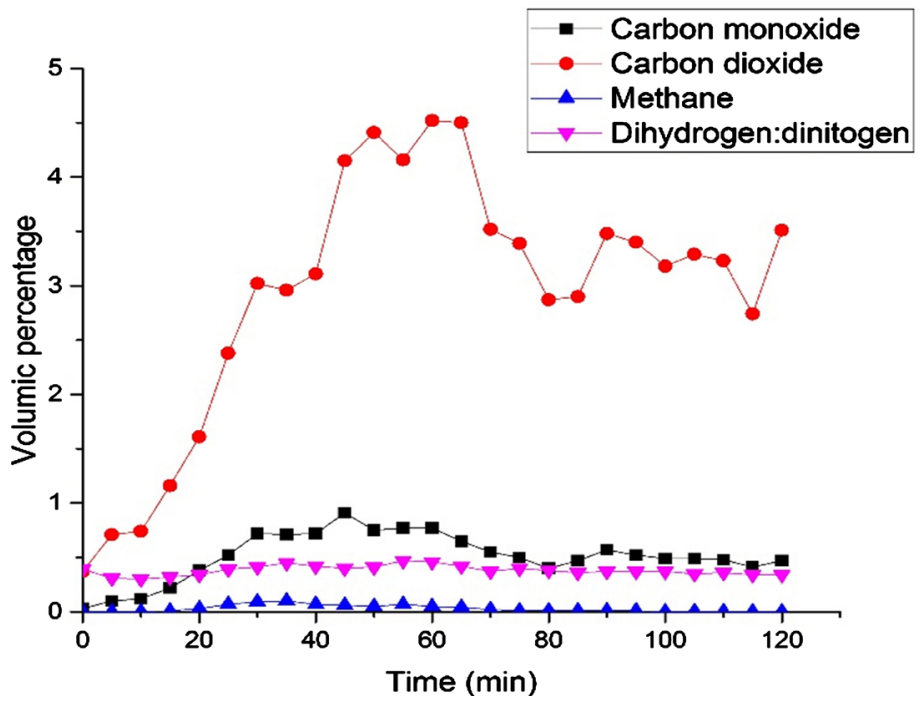

Figure 16. Proportions of gases produced by combustion as a function of time.

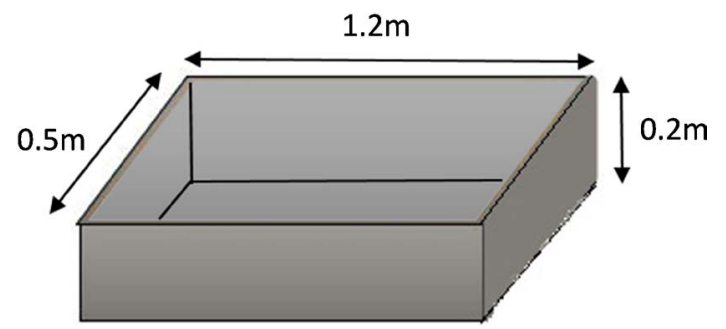

Figure 17. 3D view of the coal tank. 
- Establishment for each block equations of the balance of heat flows and boundary conditions: definition of elementary models.

- Determination of the coefficients intervening in these different relations.

The nodal method consists of defining isothermal zones. Thus, each zone constitutes a node. We will start by making a sample after the discretization (the geometry chosen for each node is cubic).

\subsubsection{Simplifying Hypotheses}

We consider the following assumptions:

- Conduction transfers are unidirectional.

- The thermo-physical properties of the materials are constant.

- The ambient temperature is the same everywhere on the outside of the oven.

- The distribution of heat is homogeneous inside the oven.

- The properties of the air depend on the speed outside and inside they depend on the speed and the temperature.

The determination of the overall thermal behavior of the charcoal tank consists in determining the thermal behavior of the following points:

We have a total of 12 nodes to which we will determine the thermal behavior because the temperature at node $M$ is known. The nodes are numbered in Figure 18. Thus, we obtain a system composed of square matrices of order 12 . The nodes D1 and D2 are the front plane and the nodes E1 and E2 are in the rear plane.

In general, in each node we have the following equation [26]:

$$
m_{i} c_{i} \frac{\partial T_{i}}{\partial t}=\sum_{i=1}^{n} \sum_{j=1}^{m} g_{i, j}\left(T_{j}-T_{i}\right)+\dot{m}_{i} h_{a}^{e}-\dot{m}_{i} h_{a}^{s}+Q_{i}
$$

Some places of the oven exchange heat by convection and by radiation so in writing the equations in these nodes we will take it into account.

According to the heat transfer mode, the following equations are adopted:

- The conductive conductance:

$$
g_{i, j}=\frac{\lambda S}{e}
$$

- The convective conductance:

$$
h_{c}=h \cdot S
$$

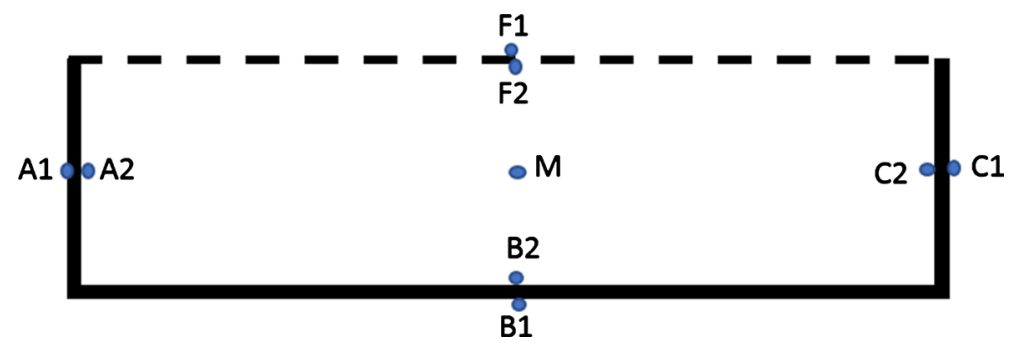

Figure 18. Characteristic points of the oven. 
- The radiative conductance:

$$
h_{r}=\varepsilon \cdot F \cdot \sigma\left(T_{j}+T_{i}\right)\left(T_{j}^{2}+T_{i}^{2}\right)
$$

All internal walls exchange heat by conduction, convection and radiation with the fuel. We get the following relation:

$$
m_{i 2} c_{i 2} \frac{\partial T_{i 2}}{\partial t}=g_{i 2, m}\left(T_{m}-T_{i}\right)+g_{i 2, i 1}\left(T_{a 1}-T_{a 2}\right)
$$

With $g_{i 1, i 2}=\frac{\lambda_{\text {fer }} \cdot S_{i}}{e_{\text {fer }}}$ for all the walls; $g_{i 2, m}=h_{a c}+h_{r-p i-c}+h_{a v c}+\frac{\lambda_{\text {char }} S_{i}}{2 e_{\text {chari }}}$ for the side walls; and $g_{i 2, m}=h_{a c}+h_{r-p i-c}+h_{a v c}+\frac{\lambda_{c h a r} S_{i}}{e_{c h a r}}$ for the bottom wall of the oven.

The outer walls exchange heat by convection and radiation with the external environment. We get the following relation:

$$
m_{i 1} c_{i 1} \frac{\partial T_{i 1}}{\partial t}=g_{i 1, i 2}\left(T_{i 2}-T_{i 1}\right)+g_{i 1, e x t}\left(T_{e x t}-T_{i 1}\right)+g_{i 1, \text { ciel }}\left(T_{\text {ciel }}-T_{i 1}\right)
$$

With $g_{a 1, a 2}=\frac{\lambda_{\text {fer }} S_{a}}{e_{\text {fer }}}$ and $g_{1, e x t}=h_{a, e x t}+h_{a v, e x t}$ and $g_{1, \text { cielt }}=h_{r-p-c i e l}$.

The discretization of these equations gives for the external walls:

$$
\begin{gathered}
m_{i 1} c_{i 1} \frac{T_{i 1}^{t+\Delta t}-T_{i 1}^{t}}{\Delta t}=g_{i 1, i 2}\left(T_{i 2}^{t+\Delta t}-T_{i 1}^{t+\Delta t}\right)+g_{i 1, e x t}\left(T_{\text {ext }}-T_{i 1}^{t+\Delta t}\right)+g_{i 1, \text { ciel }}\left(T_{\text {ciel }}-T_{i 1}^{t+\Delta t}\right) \\
\rightarrow\left(1+\alpha_{i 1, i 2}+\alpha_{i 1, \text { ext }}+\alpha_{i 1, \text { ciel }}\right) T_{i 1}^{t+\Delta t}-\alpha_{i 1, i 2} T_{i 2}^{t+\Delta t}=T_{i 1}^{t}+\alpha_{i 1, \text { ext }} T_{\text {ext }}+\alpha_{i 1, \text { ciel }} T_{\text {ciel }}
\end{gathered}
$$

With $\quad \alpha_{i 1, i 2}=\frac{\Delta t * g_{i 1, i 2}}{m_{i 1} * c_{i 1}} ; \alpha_{i 1, \text { ext }}=\frac{\Delta t * g_{i 1, \text { ext }}}{m_{i 1} * c_{i 1}}$ and $\alpha_{i 1, \text { ciel }}=\frac{\Delta t * g_{i 1, c i e l}}{m_{i 1} * c_{i 1}}$.

Likewise at the internal walls, we have:

$$
\left(1+\alpha_{i 2, i 1}+\alpha_{i 2, m}\right) T_{i 2}^{t+\Delta t}-\alpha_{i 2, i 1} T_{i 1}^{t+\Delta t}-\alpha_{i 2, m} T_{m}^{t+\Delta t}=T_{i 2}^{t}
$$

We generally have: $\alpha_{i, j}=\frac{\Delta t * g_{i, j}}{m_{i} * c_{i}}$.

\subsubsection{Heat Transfer Coefficients}

\section{- Convective heat transfer}

In the characterization of thermal transfers between any fluid and a wall, the number of Nusselt $(\mathrm{Nu})$ is used. Indeed:

$$
N u=\frac{h L_{c}}{\lambda}
$$

With $h$ the heat exchange coefficient, the characteristic length and the thermal conductivity of the fluid.

Empirical correlations make it possible to determine the Nusselt number as a function of the type and the transfer regime. In our study the type of convection inside the chamber is forced convection because of the chimney and the effect of the draft. The following relationship will then be used [27]:

$$
N u=0.5\left(1.6 R e_{D c}^{0.5}+2.733 R e_{D c}^{0.59}\right)
$$




$$
R e=\frac{\rho \times v \times D}{\mu} \text { and } D=\frac{4 \times S}{P} ;
$$

Outside the combustion chamber, we have a natural convection with the external environment. Indeed, Bernard Eyglunent, in his manual estimates that in natural convection around a vertical flat plate [28]:

$$
N u=0.59(\operatorname{Pr} \cdot G r)^{0.025} \text { for } 10^{4}<\operatorname{Pr} \cdot G r<10^{9}
$$

and

$$
\mathrm{Nu}=0.13(\mathrm{Pr} \cdot \mathrm{Gr})^{0.33} \text { for } \mathrm{Pr} \cdot \mathrm{Gr}>10^{9}
$$

The outer and inner faces of the combustion chamber exchange heat by convection with the surrounding environment. The air velocity being not negligible, we chose the Mc Adam correlation to determine the heat exchange coefficient of these faces:

$$
h_{c}=5.7+3.8 \mathrm{~V}
$$

In a charcoal fireplace the correlations used for the characteristics of the air inside are [29]:

Massive heat:

$$
C_{p}=0.9362+0.0002 * T(\mathrm{~kJ} / \mathrm{kg} \cdot \mathrm{K})
$$

Thermal conductivity:

$$
\lambda=0.00031847 * T^{0.7775}(\mathrm{~W} / \mathrm{m} \cdot \mathrm{K})
$$

Kinematic viscosity:

$$
v=\left(0.0000644 * T^{2}+0.0631 * T-9.54\right) * 10^{-6}\left(\mathrm{~m}^{2} / \mathrm{s}\right)
$$

Dynamic viscosity:

$$
\mu=0.0447 * 10^{-5} * T^{0,7775}(\mathrm{~kg} / \mathrm{m} \cdot \mathrm{s})
$$

The density:

$$
\begin{aligned}
\rho & =353 / T\left(\mathrm{~kg} / \mathrm{m}^{3}\right) \\
\operatorname{Pr} & =0.685(\text { Constant })
\end{aligned}
$$

\section{- Radiant heat transfer}

The radiative transfer coefficient between the outer wall of the pressure cooker and the celestial vault is determined by the expression [26].

$$
h_{r-p-\text { ciel }}=\frac{\sigma}{\frac{1}{\varepsilon_{p}}+\frac{1}{F_{\text {ciel }}}-1}\left(T_{f t}^{2}+T_{\text {ciel }}^{2}\right)\left(T_{f t}+T_{\text {ciel }}\right)
$$

In the case of a vertical wall with the celestial vault, the radiative Fciel form factor is deduced by the following expression [30] [31]:

$$
F_{\text {ciel }}=\frac{3 \pi+2 b}{2 \pi(3+b)}
$$


where $b$ represents a parameter, which is a function of the anisotropy of the sky. For an isotropic sky $(b=0)$ the radiative form factor corresponds to the value 0.5 .

Among the several reported correlations to determine the temperature of the celestial vault, the one proposed by Swinbank is chosen in this work [32].

$$
T_{\text {ciel }}=0.0552 T_{\text {amb }}^{1.5}
$$

where $T_{a m b}$ is the ambient temperature (K).

The radiation of the coal is quantified by the following relation [29]:

$$
F_{c}=\frac{D^{2}+2\left(H+W_{i}\right)^{2}-2\left(H+W_{i}\right) \sqrt{D^{2}+\left(H+W_{i}\right)^{2}}}{D^{2}}
$$

\subsection{Comparison of Numerical and Experimental Results and Validation of the Theoretical Model}

The duration of both numerical simulation and experimental study is two (02) hours.

\subsubsection{Comparison of Theoretical and Experimental Temperature Profiles of Combustion Temperatures}

In order to compare our theoretical results with the experimental results, we interpolated the fuel temperature in order to integrate it into our simulation code.

Figure 19 shows that the $5^{\text {th }}$ order polynomial interpolation curve makes a good approximation of the combustion temperature. In fact, apart from the first two points whose relative errors are $10.4 \%$ and $9.3 \%$, the other values have relative errors of less than $5 \%$. This curve will be used to determine fuel temperatures regardless of the time in the numerical study.

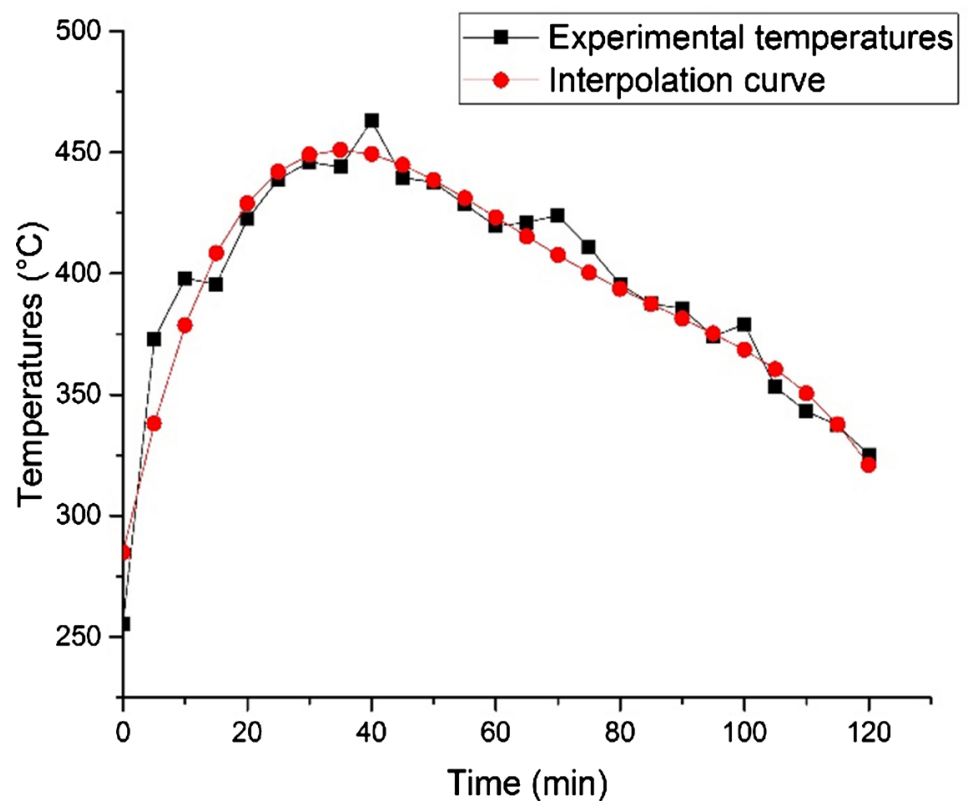

Figure 19. Experimental fuel temperatures and interpolation curve. 


\subsubsection{Comparison of Theoretical and Experimental Temperature Profiles of External Sidewall Temperatures}

Figure 20 shows the theoretical and experimental temperature profiles of the sidewalls.

Both profiles have a first phase of rapid growth and a second phase of decay a little slow. During these two phases, the temperature profiles remain close, indicating that the theoretical model manages to describe the overall behavior of the side walls. The relative errors are large during the first thirty $(30 \mathrm{~min})$ and about $6 \%$ after. This is explained by the fact that in the experimental study, the early charcoal burning zone is centered. The combustion front has not yet reached the side walls. After thirty minutes (30 min) of combustion, all the walls are in contact with the incandescent fuel.

\subsubsection{Comparison of Theoretical and Experimental Temperature Profiles of External Wall Temperatures of the Oven}

The theoretical and experimental temperature profiles of the bottom wall of the oven are shown in Figure 21.

The temperature profiles also have a first phase of growth and a second phase of decay. During these two phases, the temperature profiles remain similar, therefore indicating that the theoretical model describes the overall behavior of the bottom wall of the coal. The relative error between the theoretical results and the experimental results is $9.68 \%$.

\subsubsection{Comparison of the Theoretical and Experimental Temperature Profiles of the Grid}

Figure 22 depicts the theoretical and experimental temperature profiles of the grid on which the products to be grilled are placed.

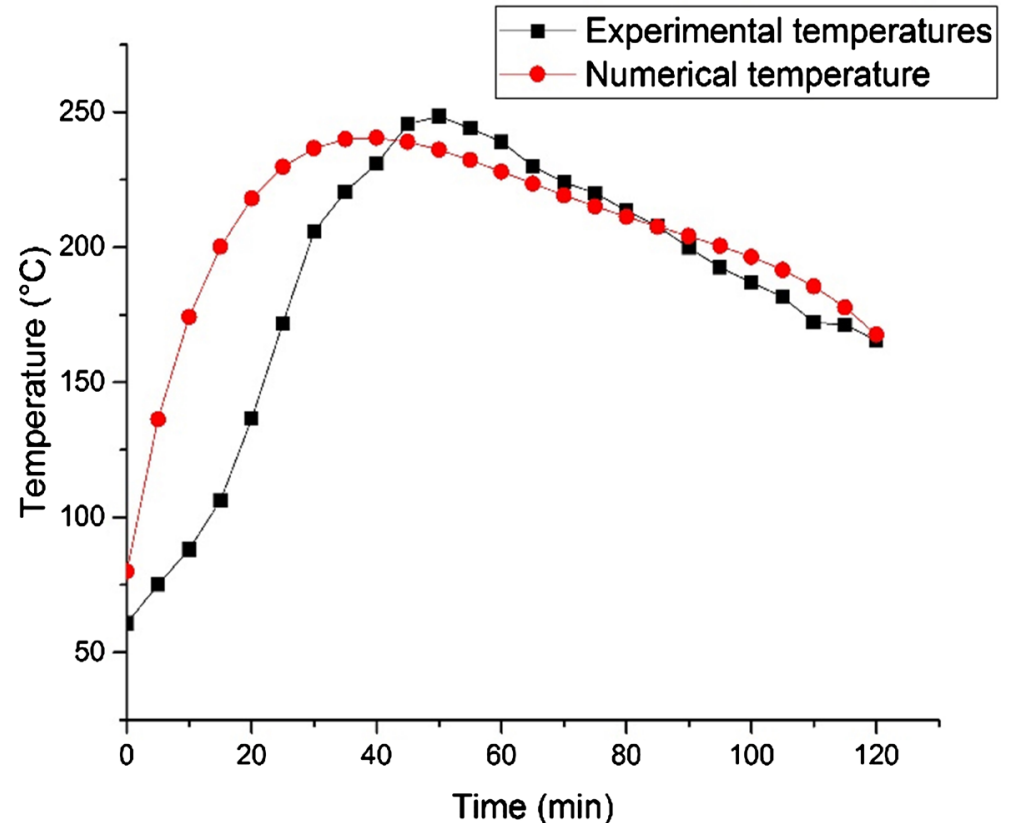

Figure 20. Experimental lateral parietal temperature profiles. 


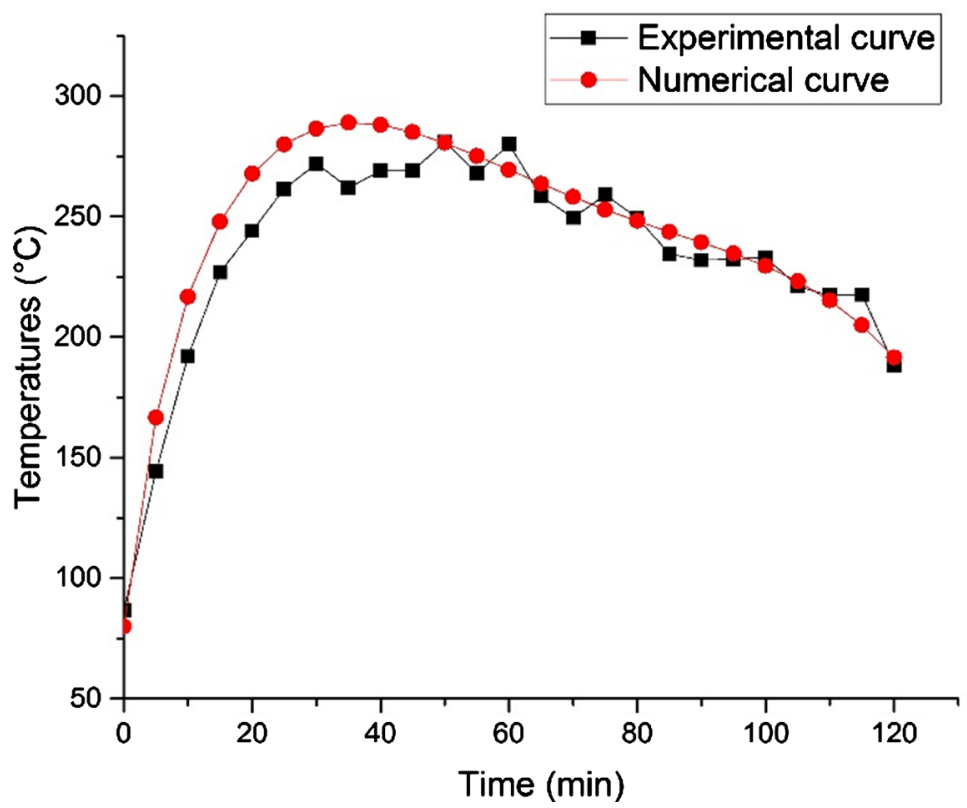

Figure 21. Profiles of external bottom wall theoretical and experimental temperature.

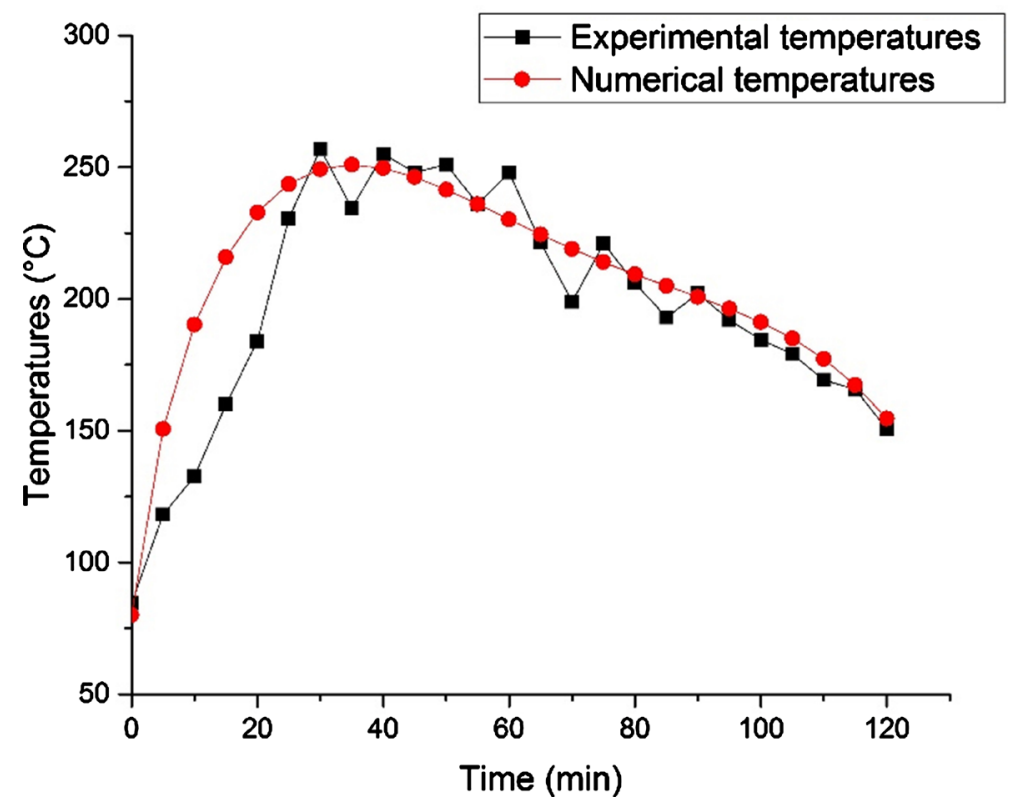

Figure 22. Temporal evolution of the theoretical and experimental temperatures of the grid.

Both profiles also have a first phase of rapid growth and a second phase of decay a little slow. During these two phases, the temperature profiles remain close, which allows us to say that our theoretical model manages to describe the overall thermal behavior of the oven grate. Since the combustion zone is centered at the beginning, the walls are not in contact with the incandescent coal, which explains the small variation of the experimental temperature. The relative error between the experimental and theoretical temperatures is therefore large at first but after 20 minutes the values decrease to about $7.19 \%$. 


\subsubsection{Comparison of Theoretical and Experimental Temperature Profiles of oven Temperatures}

Through Figure 23 and Figure 24, we can observe the experimental and theoretical temperature profiles of the oven.

These two figures show us that all the temperatures follow that of the fuel. With the increase of the fuel's temperature, the temperatures of the other parts keep increasing as well. The theoretical temperature under the oven remains greater than those of the side walls and those of the grid as in the experimental study. The theoretical temperatures of the different walls as well as that of the grid are similar. These results allowed us to validate our theoretical model of the oven.

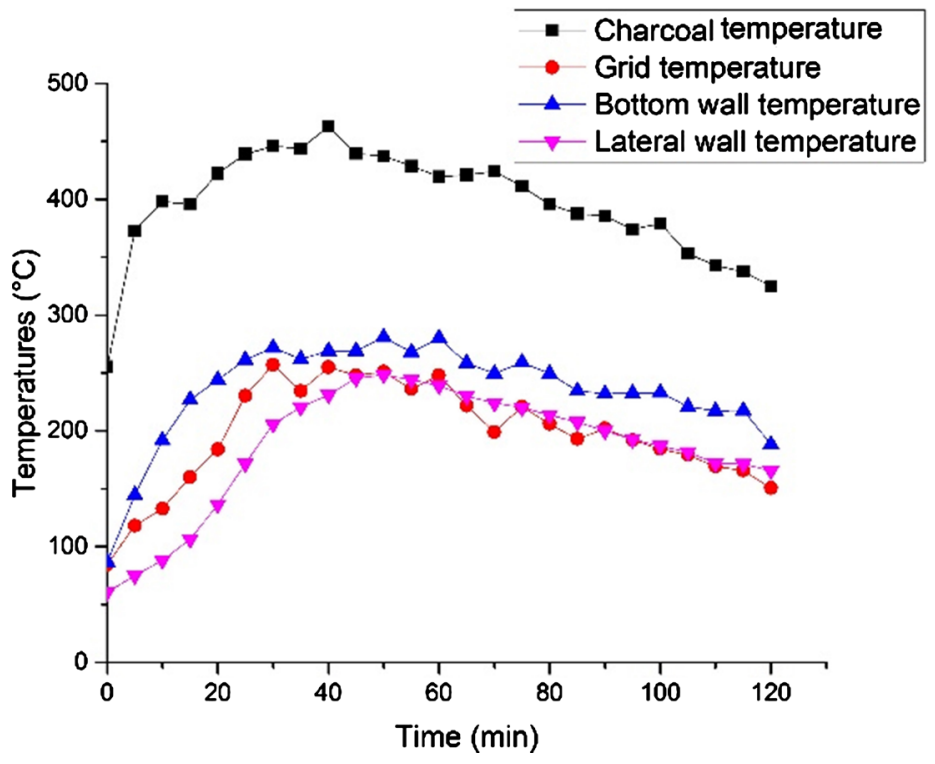

Figure 23. Experimental temperature profiles.

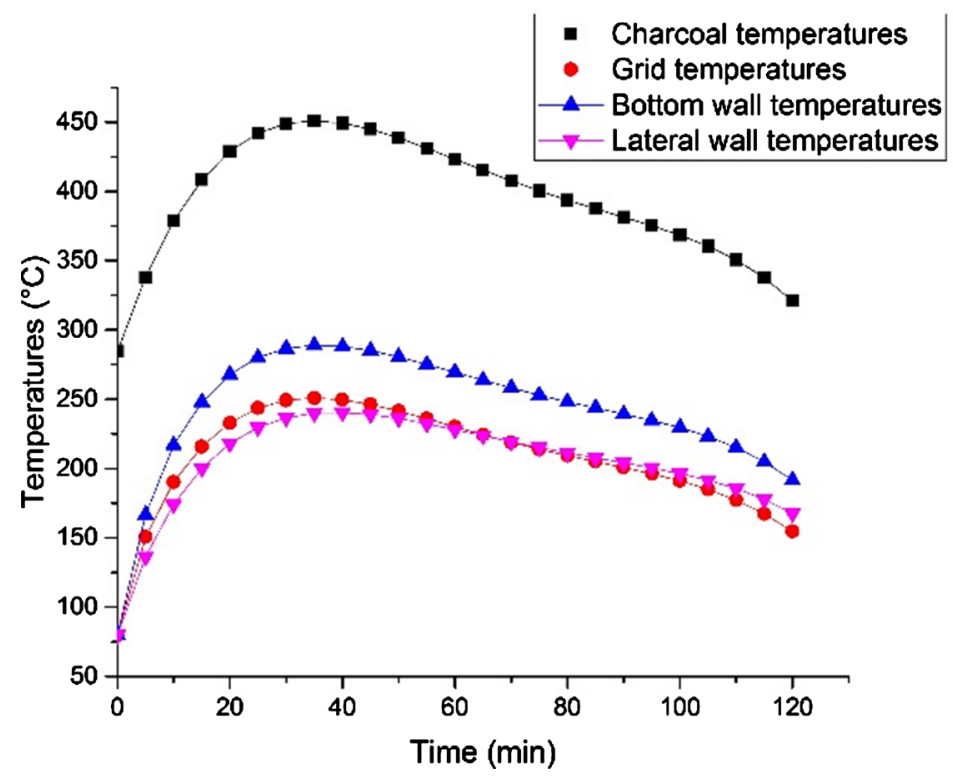

Figure 24. Numerical temperature profiles. 


\subsection{Quantification of the Energy Lost by the Walls and the Corresponding Charcoal Mass}

From the temporal profile of the temperatures, the energy lost by the oven walls can be calculated. In this study, energy stored in the walls and energy lost to outside environment were considered lost energy. The amount of energy lost per time unit is represented by the following figure.

Figure 25 shows that the amount of energy lost is very large from the beginning. This is due to the high conductivity of the iron sheet. Charcoal heating value is estimated by $\mathrm{P}$. Khummongkol et al. [33]: $H_{v}=2.6 \times 10^{4} \mathrm{~kJ} / \mathrm{kg}$. The amount of energy lost with the oven walls during the two hours of experience is $Q=3.82 \times 10^{4} \mathrm{~kJ}$, which gives about $m_{\text {lost }}=1.47 \mathrm{~kg}$ on $3 \mathrm{~kg}$ of burned charcoal. This shows that almost half of the burned charcoal is lost through the barbecue walls.

\section{Conclusion}

The experimental and numerical study carried out in this work made it possible to understand the thermal behavior of a model of oven commonly used in the sector of grilling in Burkina Faso. From this study, it appears that the oven has low energy efficiency due to the thermophysical properties of the materials used and the poor combustion of charcoal. As a consequence, this results in wasted energy and the discomfort of users exposed to high temperatures (over $200^{\circ} \mathrm{C}$ ). In addition, the amount of energy lost by the oven walls represents about half of the energy produced by the combustion of charcoal. This study clearly shows that these ovens need to be improved in terms of energy efficiency, which will be the subject of our next work.

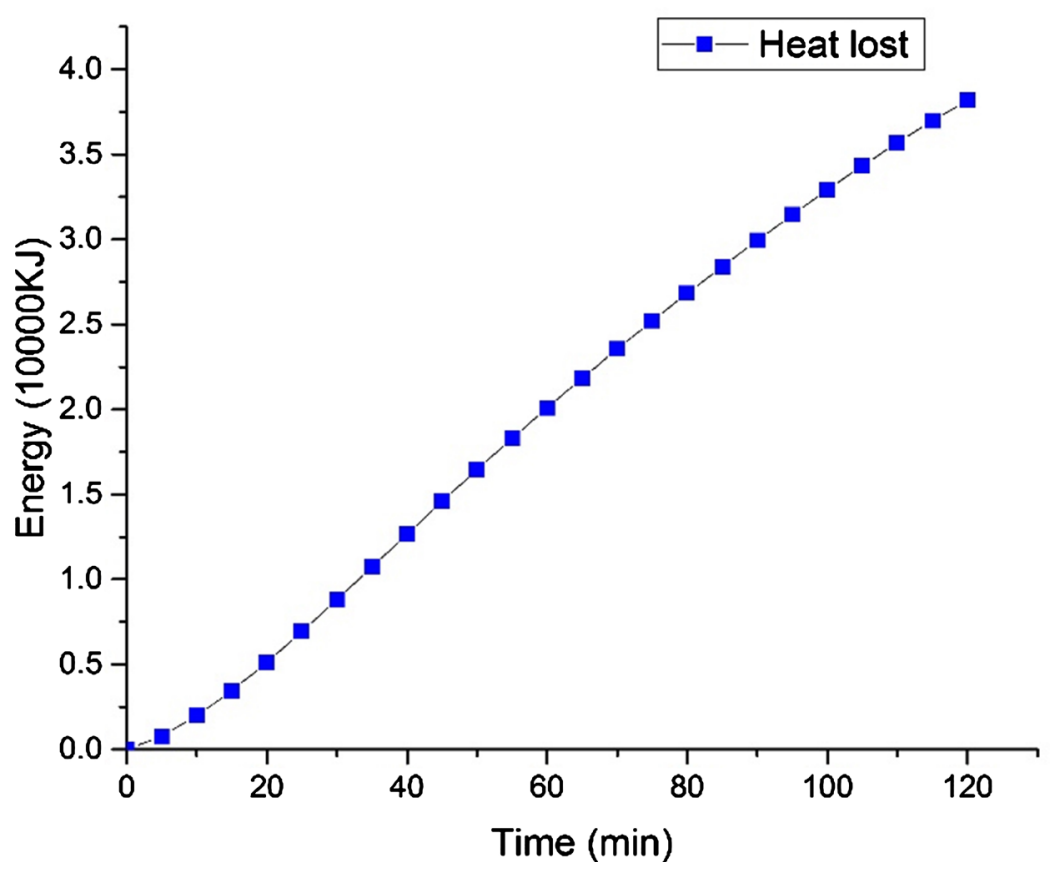

Figure 25. Temporal heat lost with barbecue walls. 


\section{Acknowledgements}

The authors express their deep gratitude to the International Science Program (ISP) for their financial support.

\section{Conflicts of Interest}

The authors declare no conflicts of interest regarding the publication of this paper.

\section{References}

[1] Suresh, R., Singh, V., Malik, J., Datta, A., et al. (2016) Evaluation of the Performance of Improved Biomass Cooking Stoves with Different Solid Biomass Fuel Types. Biomass and Bioenergy, 95, 27-34. https://doi.org/10.1016/j.biombioe.2016.08.002

[2] Hummel, D. (2015) Climate Change, Land Degradation and Migration in Mali and Senegal: Some Policy Implications. Migration and Development, 5, 211-233. https://doi.org/10.1080/21632324.2015.1022972

[3] Awojobi, O.N. and Tetteh, J. (2017) The Impacts of Climate Change in Africa: A Review of the Scientific Literature. Journal of International Academic Research for Multidisciplinary, 5, 39-52.

[4] Chersich, M.F., Wright, C.Y., Venter, F., Rees, H., Scorgie, F. and Erasmus, B. (2018) Impacts of Climate Change on Health and Wellbeing in South Africa. International Journal of Environmental Research and Public Health, 15, 1884. https://doi.org/10.3390/ijerph15091884

[5] Pyhälä, A., Fernandez-Llamazares, A., Lehvävirta, H., Byg, A., Ruiz-Mallén, I., Salpeteur, M. and Thornton, T.F. (2016) Global Environmental Change: Local Perceptions, Understandings and Explanations. Ecology and Society, 21, 3-25. https://doi.org/10.5751/ES-08482-210325

[6] Hallegatte, S., Fay, M. and Barbier, E.B. (2018) Poverty and Climate Change. Introduction, Environment and Development Economics, 23, 217-233. https://doi.org/10.1017/S1355770X18000141

[7] Ministère de l'Environnement et du Développement Durable (2013) Quelles stratégie pour le renforcement de la résilience des populations face au changement climatique en vue d'assurer une sécurité alimentaire durable. Ouagadougou.

[8] Kshirsagar, M.P. and Kalamkar, V.R. (2014) A Comprehensive Review on Biomass Cookstoves and a Systematic Approach for Modern Cookstove Design. Renewable and Sustainable Energy Reviews, 30, 580-603.

https://doi.org/10.1016/j.rser.2013.10.039

[9] IRSAT (2013) Catalogue des technologies et innovations du Burkina Faso, 2 ère édition.

[10] IRSAT (2014) Catalogue des technologies et innovations du Burkina Faso, 1 ème édition.

[11] Birzer, C., Medwell, P., MacFarlane, G., Read, M., Wilkey, J., Higgins, M. and West, T. (2014) A Biochar-Producing, Dung-Burning Cookstove for Humanitarian Purposes. Procedia Engineering, 78, 243-249.

https://doi.org/10.1016/j.proeng.2014.07.063

[12] Benka-Coker, M.L., Tadele, W., Milano, A., Getaneh, D. and Stokes, H. (2018) A Case Study of the Ethanol Clean Cook Stove Intervention and Potential Scale-Up in Ethiopia. Energy for Sustainable Development, 46, 53-64.

https://doi.org/10.1016/j.esd.2018.06.009 
[13] Vitali, F., Parmigiani, S., Vaccari, M. and Collivignarelli, C. (2013) Agricultural Waste as Household Fuel: Techno-Economic Assessment of a New Rice-Husk Cookstove for Developing Countries. Waste Management, 33, 2762-2770. https://doi.org/10.1016/j.wasman.2013.08.026

[14] Kimemia, D. and Annegarn, H. (2011) An Urban Biomass Energy Economy in Johannesburg, South Africa. Energy for Sustainable Development, 15, 382-387. https://doi.org/10.1016/j.esd.2011.10.002

[15] Sedighi, M. and Salarian, H. (2017) A Comprehensive Review of Technical Aspects of Biomass Cookstoves. Renewable and Sustainable Energy Reviews, 70, 656-665. https://doi.org/10.1016/j.rser.2016.11.175

[16] Giwa, A., Alabi, A., Yusuf, A. and Olukan, T. (2017) A Comprehensive Review on Biomass and Solar Energy for Sustainable Energy Generation in Nigeria. Renewable and Sustainable Energy Reviews, 69, 620-641.

https://doi.org/10.1016/j.rser.2016.11.160

[17] Global Alliance for Clean Cookstoves (2017) Handbook for Boimass Cookstove Research, Design and Development: A Practical Guide to Implementing Recent Advances. Massachusetts Institute of Technology D-Lab.

[18] Brady, M.P., Banta, K., Mizia, J., Lorenz, N., Leonard, D.N., Yamamoto, Y., Defoort, M. and Keiser, J.R. (2017) Alloy Corrosion Considerations in Low-Cost, Clean Biomass Cookstoves for the Developing World. Energy for Sustainable Development, 37, 20-32. https://doi.org/10.1016/j.esd.2016.12.002

[19] Shen, G. (2016) Changes from Traditional Solid Fuels to Clean Household Energies: Opportunities in Emission Reduction of Primary PM 2.5 from Residential Cookstoves in China. Biomass and Bioenergy, 86, 28-35. https://doi.org/10.1016/j.biombioe.2016.01.004

[20] Beohar, H., Gupta, B., Sethi, D.V.K., Pandey, D.M. and Parmar, H. (2012) Effect of Air Velocity, Fuel Rate and Monster Content on the Performance Updraft Biomass Gasifier Using Fluent Tool. International Journal of Modern Engineering Research, 2, 3622-3627.

[21] Georges, O.G., Mamadou, O. and Tenga, R. (2004) Atelier Régional de Capitalisation de L'Expérience Sahélienne en Matière de Carbonisation Améliorée et D'agglo-briquetage.

[22] Arora, P., Das, P., Jain, S. and Kishore, V.V.N. (2014) A Laboratory Based Comparative Study of Indian Biomass Cookstove Testing Protocol and Water Boiling Test. Energy for Sustainable Development, 21, 81-88. https://doi.org/10.1016/j.esd.2014.06.001

[23] Arora, P. and Jain, S. (2016) Review of Chronological Development in Cookstove Assessment Methods: Challenges and Way Forward. Renewable and Sustainable Energy Reviews, 55, 203-220. https://doi.org/10.1016/j.rser.2015.10.142

[24] Sutar, K.B., Kohlin, S., Ravi, M.R. and Ray, A. (2015) Biomass Cookstoves: A Review of Technical Aspects. Renewable and Sustainable Energy Reviews, 41, 1128-1166. https://doi.org/10.1016/j.rser.2014.09.003

[25] Montrol, T., Jay, J., Xin, S., Knikker, R. and Decrescenzo, M.-L. (2012) Construction d'un modèle thermique nodal pour la phase de prédimensionnement d'un équipement roue et frein aéronautique: Méthodologie et simplifications, Casablanca: 2ème Congrès del'Association Marocaine de Thermique Efficacité énergétique dans l'industrie.

[26] Compaore, A. (2018) Etude des performances thermiques d'un habitat type du Burkina Faso. Application: Contribution à la mise en place d'une reglementation thermique. Université OuagaI Pr Joseph KI ZERBO, Ouagadougou.

[27] McCarty, N.A. and Bryden, K.M. (2016) A Generalized Heat-Transfer Model for 
Shielded Fire. Energy for Sustainable Development, 33, 96-107. https://doi.org/10.1016/j.esd.2016.03.003

[28] Eyglunent, B. (2003) Manuel de thermique-Théorie et pratique, Hermès-Lavoisier.

[29] Kshirsagar, M.P. and Kalamkar, V.R. (2015) A Mathematical Tool for Predicting Thermal Performance of Natural Draft Biomass Cookstoves and Identification of a New Operational Parameter. Energy, 93, 188-201. https://doi.org/10.1016/j.energy.2015.09.015

[30] Ivanova, S.M. (2013) Estimation of Background Diffuse Irradiance on Orthogonal Surfaces under Partially Obstructed Anisotropic Sky Part I-Vertical Surfaces. Solar Energy, 95, 376-391. https://doi.org/10.1016/j.solener.2013.01.021

[31] Ramírez-Faz, J., Casares, F.J. and Lopez-Luque, R. (2015) Development of Synthetic Hemispheric Projections Suitable for Assessing the Sky View Factor on Vertical Planes. Renewable Energy, 74, 279-286. https://doi.org/10.1016/j.renene.2014.08.025

[32] Boubghal, S.O.A. (2008) Etude paramétrique d'un capteur solaire plan à air destiné au séchage, (Partie: 2). Revue des Energies Renouvelables SMSTS’08 Alger. 255-26.

[33] Khummongkol, P., Wibulswas, P. and Bhaitacharya, S.C. (1988) Modeling of a Charcoal Cook Stove. Energy, 13, 813-821. https://doi.org/10.1016/0360-5442(88)90086-2 


\section{Nomenclature}

$\varepsilon:$ Emissivity of the wall

$\lambda$ : Thermal conductivity $\left(\mathrm{W} \cdot \mathrm{m}^{-1} \cdot \mathrm{K}^{-1}\right)$

$\rho:$ Density $\left(\mathrm{kg} \cdot \mathrm{m}^{-3}\right)$

$v:$ Kinematic viscosity $\left(\mathrm{m}^{2} \cdot \mathrm{s}^{-1}\right)$

$\sigma$ : Stefan Boltzmann constant $\left(5.67 \times 10^{-8} \mathrm{~m}^{-2} \cdot \mathrm{K}^{-4}\right)$

$\mu$ : Dynamic viscosity

e:Characteristic thickness $(\mathrm{m})$

$C_{\dot{i}}$ : Massive heat $(\mathrm{kJ} / \mathrm{kg} \cdot \mathrm{K})$

$D$ : Hydraulic diameter (m)

$F_{\text {ciei }}$ Sky form factor

$g_{i, j}:$ Thermal conductance

Gr. Grashof

$h_{c}$ : Convection heat transfer coefficient $\left(\mathrm{W} \cdot \mathrm{m}^{-2} \cdot \mathrm{K}^{-1}\right)$

$h_{r}:$ Radiative conductance $\left(\mathrm{W} \cdot \mathrm{m}^{-2} \cdot \mathrm{K}^{-1}\right)$

$m_{i}$ : Massa of node I $(\mathrm{kg})$

$N u$ : Nusselt number

$P$. Perimeter

Pr. Prandlt number

Re: Neynold number

$S$ : Surface $\left(\mathrm{m}^{2}\right)$

$T_{a m b}$ : Ambient temperature (K)

$T_{\text {ciei: }}$ Sky temperature (K)

$V:$ Air velocity $(\mathrm{m} / \mathrm{s})$ 